\title{
Kidney Biopsy: An Experience from Tertiary Hospital
}

\author{
Madhav Ghimire,' Bishnu Pahari,, Navaraj Paudel,' Gayatri Das,, Gopal Chandra Das,' Sanjib Kumar Sharma² \\ 'Department of Nephrology, ${ }^{2}$ Department of Cardiology, College of Medical Sciences Teaching Hospital, Bharatpur, Chitwan, \\ Nepal.
}

\section{ABSTRACT}

Introduction: Kidney Biopsy is an important diagnostic tool in Nephrology. It is useful in Nephrology in terms of diagnosis, prognosis and management. There is little information on renal biopsy data from central Nepal. We describe our center`s experience in kidney biopsy in term of histological patterns, complications and outcomes.

Methods: We prospectively analyzed the biopsies data of patients over a period of one and half year. All kinds of kidney disease patients were included for kidney biopsy, irrespective of their clinical syndromes and underlying diagnosis.

Results: A total of 75 biopsies were analyzed. Majority of them were females; 42 (56\%). Most of the biopsies; 63 (84\%) were from younger subjects $\leq 45$ years and majority of them fell in the age group 11-20 years. Most common clinical renal syndrome to undergo biopsy was Sub Nephrotic range Proteinuria in 40 (53.3\%). Among comorbid conditions, 40 (53.3\%) had Hypertension. The most common histological pattern seen was Mesangial proliferative Glomerulonephritis seen in 18 (24\%). Among complications associated with the procedure, macroscopic hematuria was seen in 5 $(6.7 \%)$ cases and clinically significant perinephric hematoma causing pain was seen in $4(5.3 \%)$. There was no mortality associated with biopsy procedure.

Conclusions: Sub Nephrotic range Proteinuria was the commonest clinical renal Syndrome observed. In terms of renal histology, Mesangial Proliferative Glomerulonephritis (MesPGN) was the commonest histological pattern observed. Kidney biopsy is a safe procedure without any significant adverse events.

Keywords: kidney biopsy; meningeal proliferative glomerulonephritis; sub nephrotic range proteinuria.

\section{INTRODUCTION}

Kidney biopsy is an important armamentarium in the field of clinical Nephrology. Kidney biopsy is useful not only in making a specific diagnosis but also in assessing and prognosticating the disease activity and finally formulating a treatment plan. ${ }^{1}$ The histological study of kidney biopsy has maintained its charm and is still the gold standard for the diagnosis of renal disease till date. ${ }^{2}$ Unfortunately we don't have a central renal biopsy registry in Nepal. Renal biopsy is a relatively safe procedure, with life-threatening complications occurring in less than $0.1 \%$ of biopsies. ${ }^{3}$ The present study was conducted with an aim to study the clinical renal

Correspondence: Dr Madhav Ghimire, Department of Nephrology, College of Medical Sciences Teaching Hospital, Bharatpur, Chitwan, Nepal. Email: madhavghimirenp@yahoo.com, Contact number: $+977-98550-60179$ 
syndromes, histopathological patterns, complications and outcomes of kidney biopsy procedure performed in a medical college teaching hospital from central Nepal.

\section{METHODS}

A prospective, descriptive study of kidney biopsy was carried out. All kinds of kidney disease patients, irrespective of clinical syndromes; who were biopsied were included in the study. Data were collected from 75 consecutive renal biopsy patients over a period of one and half year; from June 2011 to November 2012 at the Nephrology Unit, College of Medical Sciences Teaching hospital, Nepal. The indications of renal biopsy in the study cases were as per the standard indication. Patients with clinical features suggestive of diabetic nephropathy were excluded unless there were atypical features. Using the self-adjustable, automated, spring loaded Gun biopsy needle of 16-18 G size (Bard Monotopy USA 16$18 \mathrm{G})$, Nephrology Residents performed all the biopsies, guided by the ultrasonographic localization of kidneys by the Radiology Residents. Two cores of renal tissue were removed during the biopsy procedure, one for light microscopy which was kept in N/10 Formal saline in and another core for Immunofluorescence which was kept in Michel media and then transported to Ranbaxy Clinical Reference Laboratories in India where they were examined for light microscopy and Immunofluorescence (IF). Patients were monitored in the nephrology ward for 24 hours after the biopsy for observation of any complications. Data including various clinical renal syndromes, comorbidities, histological patterns, complications and outcomes associated with kidney biopsies. Data were entered in a designated profroma and transferred to a Microsoft Excel spreadsheet for statistical analysis. The approval to conduct the study was granted by the Ethical Committee of the hospital and a written consent was taken from each patient prior to the biopsy procedure, after explaining the risk and benefit of the procedure and the possible complications of the procedure.

\section{RESULTS}

A total of 75 consecutive biopsies were analyzed over a period of one and half year. The mean age of the patient was $30.34 \pm 12.5$ years. The age range of patients undergoing renal biopsy was three years to 78 years. Majority of the biopsies performed were in females $56 \%(n=42)$. The male to female ratio was 0.8 . The other major results of the study are projected in tabulated form.

Out of 75 renal biopsies, $11(14.7 \%)$ biopsies were performed in children between one to 15 years of age. The youngest case to undergo renal biopsy was a child of three years with a clinical diagnosis of
Steroid resistant nephrotic syndrome. Sub Nephrotic range proteinuria was the most common indication for renal biopsy which was present in 40 (53.3\%) cases, followed by Nephrotic range proteinuria 35 (46.7\%) cases and Lupus Nephritis in 11 (14.7\%) cases.The commonest comorbidity associated with the clinical renal syndrome was hypertension in 40 (53.3\%) followed by hypothyroidism, present in 15 (20\%) cases. The most common histological pattern seen in kidney biopsy was Mesangial proliferative glomerulonephritis (MesPGN) seen in 18 (24\%) followed by Minimal change disease seen in 16 (21.3\%). In Mesangial proliferative glomerulonephritis (MesPGN) group, 9 (12\%) cases were due to Idiopathic MesPGN, 4 (5.3\%) cases were secondary to SLE and $5(6.7 \%)$ cases were secondary to $\lg$ A Nephropathy.

\begin{tabular}{|c|c|c|}
\hline Mean age (years) & & $0.34 \pm 12.5$ years \\
\hline Male: Female & & 0.8 \\
\hline Proportion of subject & Number & Percentage \\
\hline$\leq 10$ years & 2 & $2.7 \%$ \\
\hline $11-20$ years & 23 & $30.7 \%$ \\
\hline $21-30$ years & 18 & $24.0 \%$ \\
\hline $31-40$ years & 15 & $20.0 \%$ \\
\hline $41-50$ years & 7 & $9.3 \%$ \\
\hline $51-60$ years & 6 & $8.0 \%$ \\
\hline $61-70$ years & 3 & $4.0 \%$ \\
\hline $71-80$ years & 1 & $1.3 \%$ \\
\hline$\leq 45$ years & 63 & $84.0 \%$ \\
\hline $46-80$ years & 12 & $16.0 \%$ \\
\hline
\end{tabular}

Table 2. Indications of Renal biopsy.

\begin{tabular}{|c|c|c|}
\hline Indication of renal biopsy & Number & Percentage \\
\hline $\begin{array}{l}\text { Sub Nephrotic range } \\
\text { proteinuria }\end{array}$ & 40 & $53.3 \%$ \\
\hline Nephrotic Range proteinuria & 35 & $46.7 \%$ \\
\hline $\begin{array}{l}\text { Rapidly Proliferative Renal } \\
\text { Failure }\end{array}$ & 14 & $18.7 \%$ \\
\hline Lupus Nephritis & 11 & $14.7 \%$ \\
\hline Chronic Glomerulonephritis & 9 & $12.0 \%$ \\
\hline Acute Nephritic Syndrome & 7 & $9.3 \%$ \\
\hline Malignant Infiltration & 1 & $1.3 \%$ \\
\hline
\end{tabular}

Table 3. Co-morbidities.

\begin{tabular}{|lcc|}
\hline Comorbidities & Number & Percentage \\
Hypertension & 40 & $53.3 \%$ \\
Hypothyroidism & 15 & $20.0 \%$ \\
Type 2 DM & 3 & $4.0 \%$ \\
\hline
\end{tabular}




\section{DISCUSSION}

There is limited data on spectrum of biopsy proven kidney disease from Nepal. The prevalence of biopsy proven renal disease underestimates the true prevalence of the renal disease, as not all patients with renal disease are biopsied. We observed that most of the biopsies were done in young cases below the age of 45 years which comprised $84 \%(n=63)$ of the biopsies and $14.7 \%$ cases $(n=11)$ were in the pediatric age group (1 to 15 years). This low prevalence of kidney biopsy in pediatric age group in our part, indirectly suggested either a higher age of onset of the renal diseases or strict criteria set for renal biopsy or a hesitancy and fear of doing biopsy in the pediatric patients. Similar observations were reported from Czech, ${ }^{4}$ Serbia, ${ }^{5}$ Italy, ${ }^{6}$ France $^{7}$ and Romania. ${ }^{8}$ However in Korea ${ }^{9}$ and Japan, ${ }^{10}$ the number of pediatric biopsy cases were quite high $40.5 \%$ and $20 \%$ respectively.

\begin{tabular}{|lll|}
\hline \multicolumn{2}{|l|}{ Table 4. Histological pattern. } & \\
\hline Histological Pattern & Number & Percentage \\
Mesangioproliferative & 18 & $24.0 \%$ \\
Glomerulonephritis & & \\
Minimal Change Disease & 16 & $21.3 \%$ \\
Membranous Nephropathy & 11 & $14.7 \%$ \\
Lupus Nephritis & 10 & $13.3 \%$ \\
Chronic Glomerulonephritis & 7 & $9.3 \%$ \\
Chronic Interstitial Nephritis & 7 & $9.3 \%$ \\
Membranoproliferative & 6 & $8.0 \%$ \\
Glomerulonephritis & & \\
IgA Nephropathy & 5 & $6.7 \%$ \\
Diffuse Proliferative & 5 & $6.7 \%$ \\
Glomerulonephritis & & \\
Focal Segmental & 4 & $5.3 \%$ \\
Glomerulosclerosis & & $4.0 \%$ \\
Cresentric & 3 & \\
Glomerulonephritis & &
\end{tabular}

We observed a female predominance, which indirectly signifies that the females were at higher risk of kidney disease. This may be due to the high number of lupus nephritis cases $10(13.3 \%)$ where all subjects were females or this might be because of inherent female factors, which needs further genetic study. Similar to our study, a female predominance was also documented in a study from Egypt. ${ }^{11}$ However this finding was in contrast to most other studies from the European countries like in Serbia ${ }^{5}$ and in Romania, ${ }^{8}$ where an equal gender distribution was seen. Male gender predominance as seen in studies from Italian ${ }^{6}$ and Czech. ${ }^{4}$

Sub Nephrotic range proteinuria was the most common indication for renal biopsy, seen in 40 (53.3\%) of our cases which is a unique finding not been observed in previous studies. In contrast to our study, many other countries in Arabian region, like Jordan ${ }^{12}$ and United Arab Emirates, ${ }^{13}$ found Nephrotic Syndrome to be the major indication of renal biopsy seen in $51.6 \%$ and $54 \%$ respectively. Even outside the Arab world, there was dominance of nephrotic syndrome to be the first indication for the renal biopsy, as shown by studies from Serbia5 (36.92\%), Romania8 (52.3\%), Senegal ${ }^{14}$ (67\%) and Brazil15 (42\%).However, it is too early to comment on this issue, because of the small sample size of our study. Nephrotic Syndrome was present in $35(46.7 \%)$ of the cases, being the second commonest indication for the renal biopsy.

\begin{tabular}{|lcc|}
\hline \multicolumn{3}{|l|}{ Table 5. Complications and outcome. } \\
\hline Complication & Number & Percentage \\
Macroscopic hematuria & 5 & $6.7 \%$ \\
$\begin{array}{l}\text { Clinically significant } \\
\text { perinephric hematoma }\end{array}$ & 4 & $5.3 \%$ \\
$\begin{array}{l}\text { causing pain } \\
\text { Mortality }\end{array}$ & None \\
\hline
\end{tabular}

The classical acute Nephritic Syndrome was seen in less number of cases accounting for 7 (9.3\%) of cases, which is similar to an old Italian survey which also showed that nephritic syndrome accounted for only $4.02 \%$ of the cases. ${ }^{6}$ The reason behind this low prevalence of classical acute Nephritic Syndrome is unknown.

Eastern countries showed variable results in term of histological pattern in kidney biopsies. Studies from China $^{16,17}$ and Korea ${ }^{9}$ revealed that $\lg \mathrm{A}$ nephropathy was the most common pathological abnormality, accounting for nearly $50.7 \%$ and $28 \%$ of the cases respectively. Similarly in Australia ${ }^{18}$ and USA $^{19}$ also the most common diagnosis was IgA nephropathy, which accounted for $34 \%$ and $21 \%$ of the reported cases.

Most European studies also showed that the $\lg A$ Nephropathy was the most common pathological diagnosis, with a variable percentage; like $37 \%$ in Italy, ${ }^{6}$ $34 \%$ in Czech, ${ }^{4} 17 \%$ in Spain $^{20}$ and $15 \%$ in Lithuania. ${ }^{21}$ $\lg \mathrm{A}$ nephropathy was reported to be the commonest type of glomerulonephritis in several parts of the world, but it did not appear to be so in our study. In our study $\lg A$ nephropathy was seen only in ${ }^{5}(6.7 \%)$ cases. This may be attributed to the trend of not subjecting the patients to kidney biopsy procedure unless there is significant disease activity.

A study from Nepal by Aryal Gopi et al. ${ }^{22}$ showed MGN to be the most common form of $\mathrm{GN}(42.3 \%)$ followed by MPGN ( $21.9 \%), \operatorname{MCD}(10.2 \%), \operatorname{FSGS}(8.0 \%), \lg A$ 
nephropathy $(2.9 \%)$, post infectious GN $(2.2 \%)$, chronic GN $(2.2 \%)$, tubulointerstitial nephritis $(1.5 \%)$, lupus nephritis $(1.5 \%)$, focal proliferative GN $(1.5 \%), \mathrm{C} 1 \mathrm{q}$ nephropathy $(1.5 \%)$, primary renal amyloidosis $(1.5 \%)$ and other minor form of glomerular diseases $(2.8 \%)$. The observation in study by Gopi et al. ${ }^{22}$ And our study suggests that even within the country (Nepal), there is a great heterogeneity in histological pattern of biopsy proven kidney disease signifying regional variation of the renal disease.

In an African country (Senegal), where there is predominance of the black race, FSGS was the main diagnosis accounting for $67 \%$ of the primary glomerulonephritis. ${ }^{14}$ Similarly, FSGS is the most common form GNs in Brazil, ${ }^{23}$ India, ${ }^{24}$ Bahrain, ${ }^{25}$ Croatia, ${ }^{26}$ and Sudan. ${ }^{27}$ In contrast with these reports, the FSGS $4(5.3 \%)$ is ninth on the list as a histological pattern in our study. The most common histopathological diagnosis in Romania ${ }^{8}$ was MPGN $(29 \%)$ and that in Serbia ${ }^{5}$ was MGN (21.6\%). These variations in prevalence can be attributed to ethnic and social discrepancies in various countries.

Mesangial proliferative glomerulonephritis was the commonest histopathological diagnosis observed in our study comprising of $18(24 \%)$ of the cases which is an unique finding not been observed in previous studies, this may reflect indirectly the high prevalence of ongoing bacterial, viral, and parasitic infections associated with Mesangial proliferative glomerulonephritis, that could have affected the kidneys in our area.

MCD has a variable geographic distribution, being more common in Asia than in North America or Europe. ${ }^{28}$ In Korea ${ }^{29}$ and Thailand, ${ }^{30}$ the MCD comprised $26.6 \%$ and $45.8 \%$ of total primary glomerular diseases respectively. Similarly in our study, MCD comprised about $16(21.3 \%)$ of the total biopsies.

Studies from Italy ${ }^{6}$ and Macedonia, ${ }^{31}$ showed MGN to be the major cause of Nephrotic Syndrome accounting for $32.9 \%$ and $13.5 \%$ of the cases respectively.

Despite hypertension being the most frequent comorbid condition, only one case in our study had histological evidence of hypertensive nephrosclerosis. Similar findings were supported by a group of studies done in several countries like Brazil, ${ }^{15}$ Saudi Arabia, ${ }^{32}$ Sudan $^{27}$ and Serbia. ${ }^{5}$
Only three(4\%) cases with DM in our study, had undergone kidney biopsy and the indication for biopsy in them were nondiabetic kidney disease on top of DM. In histology also, no classical pathological features of diabetic nephropathy was found. One Diabetic subject had presented with Nephrotic Syndrome, others with Sub Nephrotic range Proteinuria and RPRF respectively. The corresponding histological pattern seen in them were MCD, Cresentric Glomerulonephritis and Idiopathic mesangioproliferative glomerulonephritis respectively.

Post biopsy procedure, we did not look for microscopic hematuria. So, its prevalence was not assessed. Excluding microscopic hematuria, the major complication observed with the biopsy procedure was macroscopic hematuria, seen in Five $(6.7 \%)$ cases. Similarly clinically significant flank pain lasting more than 24 hours was seen in Four $(5.3 \%)$ cases, for whom the Ultrasound imaging was done, which showed perinephric hematoma and all of them had associated clinical macroscopic hematuria. There was no mortality associated with biopsy procedure. The present study did not document the complications occurring after the discharge of the cases.

\section{CONCLUSIONS}

The most common indication of the kidney biopsies was Sub Nephrotic range Proteinuria followed by Nephrotic Syndrome. The rarest indication was malignant infiltration in one of the case. MesPGN was the most common histological diagnosis, representing about one quarter of the cases. In general, the present study has shown a heterogeneous pattern of renal disease within or abroad. The higher frequency of MesPGN seen in our study compared to other countries deserves further evaluation. So a larger and multicentric study is needed to draw the map of the renal diseases which are prevalent in Nepal and the information obtained from these results can be used as baseline data for making efficient policy in Nepalese population for preventing the kidney disease. Kidney biopsy is a safe procedure without any significant adverse events. Owing to the safety profile of the procedure, one should not hesitate to perform the procedure whenever indicated.

\section{ACKNOWLEDGEMENTS}

The authors would like to thank, Dr. Sandeep Garg and Dr. Satendra Raut, for their contributions during kidney biopsy procedure.

\section{REFERENCES}

1. Tompson CRV. Indications for renal biopsy in chronic kidney disease. Clinical Medicine. 2003;3:513-6.
2. Pesce F, Schena FP. Worldwide distribution of glomerular diseases: the role of renal biopsy registries. Nephrol Dial Transplant. 2010;25: 334-6. 
3. Whittier WL, Korbet SM. Timing of complications in percutaneous renal biopsy. J Am Soc Nephrol. 2004;15:142-7.

4. Rychlík I, Jancová E, Tesar V, Kolsky A, Lácha J, Stejskal J, et al. The Czech registry of renal biopsies. Occurrence of renal diseases in the years 1994-2000. Nephrol Dial Transplant. 2004 Dec;19(12):3040-9.

5. Naumovic R, Pavlovic S, Stojkovic D, Basta-Jovanovic G, Nesic V. Renal biopsy registry from a single centre in Serbia: 20 years of experience. Nephrol Dial Transplant. 2009 Mar;24(3):877-85.

6. Schena FP. Survey of the Italian Registry of Renal Biopsies. Frequency of the renal diseases for 7 consecutive years. The Italian Group of Renal Immunopathology. Nephrol Dial Transplant. 1997;12:418-26.

7. Simon P, Ramee MP, Boulahrouz R, Stanescu C, Charasse $\mathrm{C}$, Ang KS, et al. Epidemiologic data of primary glomerular diseases in western France. Kidney Int. 2004 Sep;66(3):905-8.

8. Covic A, Schiller A, Volovat C, Gluhovschi G, Gusbeth-Tatomir P, Petrica L, et al. Epidemiology of renal disease in Romania: a 10 year review of two regional renal biopsy databases. Nephrol Dial Transplant. 2006 Feb;21(2):419-24.

9. Chang JH, Kim DK, Kim HW. Changing prevalence of glomerular diseases in Korean adults: a review of 20 years of experience. Nephrol Dial Transplant. 2009;24:2406-10.

10. Research Group on Progressive Chronic Renal Disease. Nationwide and long-term survey of primary glomerulonephritis in Japan as observed in 1850 biopsied cases. Nephron. 1999;82(3):205-13.

11. Barsoum RS, Francis MR. Spectrum of Glomerulonephritis in Egypt. Saudi J Kidney Dis Transplant. 2000;11:421-9.

12. Wahbeh AM, Ewais MH, Elsharif ME. Spectrum of glomerulonephritis in adult Jordanians at Jordan university hospital. Saudi J Kidney Dis Transplant. 2008;19(6):997-1000.

13. Yahya TM, Pingle A, Boobes Y, Pingle S. Analysis of 490 kidney biopsies: data from the United Arab Emirates Renal Diseases Registry. J Nephrol. 1998 May-Jun;11(3):148-50.

14. Abdou N, Boucar D, El Hadj Fary KA, Mouhamadou M, Abdoulaye L, Mamadou Mourtala KA, et al. Histopathological profiles of nephropathies in senegal. Saudi J Kidney Dis Transpl. 2003 Apr-Jun;14(2):212-4.

15. Polito MG, de Moura LA, Kirsztajn GM. An overview on frequency of renal biopsy diagnosis in Brazil: clinical and pathological patterns based on 9617 native kidney biopsies. Nephrol Dial Transplant. 2010;24:3050-4.

16. Zhou FD, Zhao MH, Zou WZ, Liu G, Wang H. The changing spectrum of primary glomerular diseases within 15 years: a survey of 3331 patients in a single Chinese centre. Nephrol Dial Transplant. 2009 Mar;24(3):870-6.
17. Li LS, Liu ZH. Epidemiologic data of renal diseases from a single unit in China: analysis based on 13,519 renal biopsies. Kidney Int. 2004;66:920-3.

18. Briganti EM, Dowling J, Finlay M, Hill PA, Jones CL, Kincaid-Smith PS, et al. The incidence of biopsy-proven glomerulonephritis in Australia. Nephrol Dial Transplant. 2001 Jul;16(7):1364-7.

19. Swaminathan S, Leung N, Lager DJ, Melton LJ 3rd, Bergstralh EJ, Rohlinger A, et al. Changing incidence of glomerular disease in Olmsted County, Minnesota: a 30-year renal biopsy study. Clin J Am Soc Nephrol. 2006 May;1(3):483-7.

20. Rivera F, López-Gómez JM, Pérez-García R. Frequency of renal pathology in Spain 1994-1999. Nephrol Dial Transplant. 2002;17:1594-602.

21. Razukeviciene L, Kuzminskis V, Bumblyte IA, Laurinavicius A. The indications of renal biopsies and spectrum of renal diseases in five nephrological centers of Lithuania (a five-year study). Medicina (Kaunas). 2003;39 Suppl 1:1-8.

22. Aryal G, Kafle RK. Hisopathological spectrum of glomerular disease in nepal: a seven-year retrospective study. Nepal Med Coll J. 2008 Jun;10(2):126-8.

23. Malafronte $P$, Mastroianni-Kirsztajn G, Betônico GN, Romão JE Jr, Alves MA, Carvalho MF, et al. Paulista Registry of glomerulonephritis: 5-year data report. Nephrol Dial Transplant. 2006 Nov;21(11):3098-105.

24. Chandrika BK. Non-neoplastic renal diseases in Kerala, India- analysis of 1592 cases, a two year retrospective study. Indian J Pathol Microbiol. 2007;50:300-2.

25. Al Arrayed A, George SM, Malik AK, Al Arrayed S, Rajagopalan S, Al Arrayed A, et al. Renal biopsy findings in the kingdom of bahrain: a 13-year retrospective study. Saudi J Kidney Dis Transpl. 2004 Oct-Dec;15(4):503-7.

26. Batinić D, Sćukanec-Spoljar M, Milosević D, Subat-Dezulović M, Saraga M, Delmis J, et al.Clinical and histopathological characteristics of biopsy-proven renal diseases in Croatia. Acta Med Croatica. 2007 Sep;61(4):361-4.

27. Khalifa EH, Kaballo BG, Suleiman SM, Khalil EA, El-Hassan AM. Pattern of glomerulonephritis in Sudan: histopathological and immunofluorescence study. Saudi J Kidney Dis Transpl. 2004;15:176-9.

28. Sharples PM, Poulton J, White RH. Steroid responsive nephrotic syndrome is more common in Asians. Arch Dis Child. 1985;60:1014-7.

29. Choi IJ, Jeong HJ, Han DS, Lee JS, Choi KH, Kang SW, et al. An analysis of 4,514 cases of renal biopsy in Korea. Yonsei Med J. 2001 Apr;42(2):247-54.

30. Parichatikanond P, Chawanasuntorapoj R, Shayakul C, Choensuchon B, Vasuvattakul S, Vareesangthip K, et al. An analysis of 3,555 cases of renal biopsy in Thailand. J Med Assoc Thai. 2006 Aug;89 Suppl 2:S106-11. 
31. Polenakovic MH, Grcevska L, Dzikova S. The incidence of biopsy-proven primary glomerulonephritis in the Republic of Macedonia-long-term follow-up. Nephrol Dial Transplant. 2003;18(5):v26-7.
32. Huraib S, Al Khader A, Shaheen FA, Abu Aisha H, Souqiyyeh MZ, Al Mohana F, et al. The spectrum of glomerulonephritis in saudi arabia: the results of the saudi registry. Saudi J Kidney Dis Transpl. 2000 Jul-Sep;11(3):434-41. 